\title{
Neoextractivismo, megaproyectos y conflictividad en Guatemala y Nicaragua
}

Introducción

Se analiza la nueva fase del modelo económico extractivista en Guatemala y Nicaragua, países que están planteando la construcción de corredores interoceánicos con el propósito de conectar el Pacífico con el Atlántico y eventualmente competir con el canal de Panamá. La hipótesis que aquí se presenta es que los nuevos corredores, además de agilizar el comercio y dinamizar la industria maquiladora, acelerarán la conversión de estos países en espacios de nueva inversión de capital extranjero, principalmente en minería, producción de energía eólica e hidroeléctrica, así como de agrocombustibles. Los proyectos constituyen la punta de lanza del neoextractivismo agrícola-minero y del aprovechamiento de recursos estratégicos, como el agua y el viento, para la producción de energía eléctrica; rubros que interesan al capital multinacional.

Palabras clave: neoextractivismo, megaproyectos, Guatemala, Nicaragua

- Investigador de Tiempo Completo Titular C del Centro de Estudios Superiores de México y Centroamérica de la Universidad de Ciencias y Artes de Chiapas

gasoda_2000@yahoo.com.mx desde hace más de una década está siendo impulsada en América Latina a través de alianzas entre el Estado y el capital transnacional. En el marco del Tratado de Libre Comercio con México, y después con Estados Unidos y República Dominicana (DR-CAFTA), así como del Proyecto Mesoamérica, Guatemala y Nicaragua están apostando por el neoextractivismo agrícolaminero-energético, aprovechando la dotación de recursos naturales. La conclusión del Sistema de Interconexión Eléctrica de los Países de América Central, conocido como SIEPAC, ha constituido un elemento clave para la proliferación de proyectos hidroeléctricos y eólicos para ampliar el mercado de energía en la región. Se trata pues, como dice Alimonada (2011), de la naturaleza colonizada en el marco de la desnacionalización de las economías

Espiral, Estudios sobre Estado y Sociedad

Vol. xxI No. 61 I Septiembre / Diciembre de 2014 | 09 
de la región y la destrucción de la industria nacional por el capital extranjero.

En este contexto, desde hace algunos años, ahora con renovado interés, se ha venido planteando la construcción de dos megaproyectos para enlazar la comunicación entre el Pacífico y el Atlántico. En el caso de Guatemala se trata del llamado Corredor Tecnológico Interoceánico (con 336 kilómetros de extensión y 140 metros de anchura), donde se construiría una autopista, una vía férrea, y un oleoducto, transmisión de electricidad y fibra óptica, infraestructura que conectaría dos puertos: Jutiapa e Izabal, con un costo aproximado de 12000 millones de dólares. Respecto a Nicaragua, su presidente Daniel Ortega ha pronunciado su complacencia con el proyecto del Gran Canal Interoceánico, el cual ha sido concesionado al empresario chino Wang Jing, pues considera que combatirá la pobreza extrema, generará bienestar, prosperidad y felicidad al pueblo nicaragüense. Esta obra tendrá un costo estimado de 40000 millones de dólares, con una longitud de 286 kilómetros y 520 metros de anchura; y, de ser viable, su construcción concluiría en 2018.

Así las cosas, este artículo analiza el avance del modelo neoextractivista y el significado de los megaproyectos de infraestructura en el contexto de la política de posicionamiento en el proceso de globalización de los países centroamericanos; mismo que se traduce en la extracción de recursos estratégicos, con un enorme costo social, polarización del ingreso, pobreza y exclusión social, así como más subordinación a la dinámica del capital multinacional.

\section{El modelo neoextractivista en Centroamérica}

En la última década, la región centroamericana se perfila como uno de los espacios de mayor significación en el 'nuevo' modelo extractivista. Se trata, para algunos estudiosos del tema, de la segunda fase del neoliberalismo que comenzó en 
Neoextractivismo, megaproyectos y conflictividad en Guatemala y Nicaragua

el año 2000 (Zibechi, 2011). Este modelo depredador de la naturaleza y de la vida humana, altamente contaminante, permite revitalizar la acumulación de capital, al tiempo que genera fuertes tensiones sociales.

Los países centroamericanos, independientemente de la orientación política-ideológica de quien esté en el poder, han asumido la vía del modelo neoextractivista como la opción más inmediata para captar inversión extranjera directa y para engancharse al tren de la globalización, sin importar la destrucción del medio ambiente y la vida de muchas comunidades. Todos los gobiernos, ya sean de derecha, de centro o de izquierda, mantienen la idea del crecimiento económico como motor del desarrollo, cuya expresión fáctica son las exportaciones y la Inversión Extranjera Directa (IED), sin reparar en los costos sociales y ambientales. Es en este sentido que Gudynas (2012: 130-1) plantea que:

Las exportaciones y las inversiones se han vuelto mucho más importantes, y dentro de ellas, los recursos naturales tienen un papel destacado. Esta situación se debe en buena medida a la expansión del llamado "extractivismo", que incluye actividades como la explotación minera o petrolera, o los monocultivos intensivos. El extractivismo se caracteriza por la explotación de grandes volúmenes de recursos naturales, que se exportan como commodities y dependen de economías de enclave.

La instalación de megaproyectos, como los que han tenido lugar a partir del año 2000 con la puesta en marcha del Plan Puebla-Panamá, rebautizado en 2006 Proyecto Mesoamérica, ha generado diversos impactos en los territorios donde estos se han asentado; en particular, cabe destacar la ruptura de los lazos comunitarios, la destrucción de las economías regionales y la degradación de las condiciones ambientales (Composto, 2012: 16). En el caso de Guatemala, tan solo en 2013 el número de focos de conflictividad social atendidos por la Comisión Presidencial de Derechos Huma- 
nos (Copredesh) ascendió a trescientos sesenta y tres; de estos, treinta y siete fueron de alto impacto, la mayor parte en rechazo a la explotación minera y a las hidroeléctricas (Prensa Libre, 2013). Estos últimos de manera destacada en los departamentos de Huehuetenango, San Marcos, Quiché y Quetzaltenango, donde habita una población mayoritariamente indígena con altos niveles de pobreza y marginación.

Canadá se ha convertido en la punta de lanza de estos proyectos en Guatemala, sobre todo, en la explotación minera. De tener poco más del 3\% de la Inversión Extranjera Directa (IED) en 2007, salta a más del $12 \%$ en 2009 , en el contexto de la crisis. Otro salto significativo se observa en 2011, momento en que representa cerca del 30\% de IED total. En los años siguientes, Canadá mantuvo una participación superior al 20\%; hasta septiembre de 2013 había invertido casi 230 millones de dólares, lo cual representó poco más del $22 \%$ de la IED total.

Un rasgo notable de la IED es la importancia que ha venido adquiriendo el sector compuesto por los ramos agrícola, petrolero, minero y cantero. En 2007 este sector apenas alcanzaba una participación de $9 \%$, y a partir de 2008 sobrepasó el 20\%. De 2011 a 2013 es evidente el crecimiento de las inversiones en el sector: llegó a representar más del 33\% en 2012, y hasta septiembre de 2013 alcanzó casi 42\% de la IED. Estos datos se correlacionan con la relevancia cobrada por el modelo extractivo agrícola-minero en un contexto donde las commodities, principalmente el metal oro, han incrementado sus precios debido a la demanda ejercida por los principales países desarrollados, y también por el grupo de los llamados BRICS, en particular China. ${ }^{1}$

I. "El metal dorado se ha revaluado a tasas de dos dígitos durante los últimos 10 años. En promedio, su valor crece a un ritmo cercano al $20 \%$ anual, lo que lo transforma en un refugio para evitar la erosión del dinero. Mientras una onza (28.34 granos) de este commodity valía $3 / 2$ dólares en octubre de 2002, su valor asciende a mil 769 dólares 10 años después. Según datos del Consejo Mundial del Oro (CMO), la inversión en el metal amarillo aumentó 137\% interanual entre

\section{2}


Neoextractivismo, megaproyectos y conflictividad en Guatemala y Nicaragua

En el 2010, de los 120 millones de dólares de IED en agricultura, petróleo, minas y canteras, 110.8 millones fueron de origen canadiense. Aunque la información del Banco de Guatemala (2014) no está desglosada por actividad, suponemos que se trata fundamentalmente de inversión en explotación minera, dado el predominio del capital canadiense en esta rama.

\section{El proyecto minero}

Guatemala posee una extensa riqueza de minerales metálicos entre los que destacan plomo, cobre, antimonio, zinc, plata, oro y níquel. Estos minerales se encuentran mayormente en la denominada Cordillera Central que cubre un tercio del territorio nacional. Se trata de un sistema que va desde Chiapas, México, hasta las islas del golfo de Honduras. En este amplio espacio se ubican los municipios de mayor incidencia de pobreza del país, la cual va del 75\% al 99\% (Ministerio de Energía y Minas, 2004). Quizá este sea uno de los factores que haya sido decisivo para la entrada de las compañías mineras con la estrategia de ofrecer empleos, caminos, escuelas y regalías a las autoridades municipales.

El año 2000 fue el punto de inflexión para la entrada del capital minero en la región. En Guatemala, las actividades de exploración habían comenzado un poco antes de ese año; aunque las primeras estadísticas de producción de oro y plata daten de 2005. En 2000 había un registro de trece licencias de exploración y catorce de explotación. Cinco años después, las de exploración sumaban veintitrés (las de explotación se mantuvieron en la misma cifra). Para 2007 se reportaron treinta y tres licencias de exploración y dieciocho de explotación. Las licencias vigentes hasta el 31 de enero de 2012, en lo que respecta a minerales metálicos, fueron las

finales de agosto de 201 I y de 20I2. Sólo durante el segundo trimestre de este año, los Bancos Centrales de los países compraron 157 toneladas para respaldar sus reservas" (Smilovitz, 2012). 
siguientes: ochenta y dos de exploración y treinta y cuatro de explotación. Para las mismas fechas, las solicitudes de exploración sumaron trescientas sesenta y tres, y las de explotación: diecinueve. En la lista de licencias concedidas en 2012 sobresalen las siguientes empresas: Entre Mares de Guatemala; Frederick Ernest Bird; Minera San Rafael, S.A.; Mayanikel, S.A.; Tres Puentes, S.A.; y Nichromet Guatemala, S.A. En estas licencias se reporta la existencia de oro, plata, níquel, cobalto, cromo, zinc y antimonio, principalmente (Dirección General de Minería, 2003).

En el año 2005 se alcanzó una producción de 0.74 toneladas de oro y 7.07 toneladas de plata, con un valor de 91.5 y 9.9 millones de quetzales respectivamente (Ministerio de Energía y Minas, 2006). A pesar de la estadística de producción de oro, no hay registros de exportación de este metal, únicamente de plata, cuyo monto fue de 11.12 millones de dólares. El PIB correspondiente a explotación de minas y canteras únicamente representó $0.5 \%$ del total, lo cual evidencia la poca importancia económica en aquel momento.

En Guatemala se encuentra la mina de oro y plata más importante del mundo, la Montana Exploradora, de la canadiense Goldcorp Inc. Desde 2008 ha mantenido un alto ritmo de producción, acicateado por la crisis financiera y los buenos precios del metal en los mercados internacionales. Esta explotación, mejor conocida como mina Marlin, produjo 241400 onzas troy de oro en 2008, en 2011 alcanzó la mayor producción con 382400 onzas de oro, y hasta el primer semestre de 2013, había alcanzado las 100000 onzas.

Por su parte, Nicaragua ha presentado un rápido crecimiento de la minería de exportación a partir de 2005; sobre todo, de metales preciosos. En 2009 se estimaba que las concesiones mineras metálicas abarcaban 9000 kilómetros cuadrados; y hacia 2013 se habían extendido a casi 16886 kilómetros cuadros, alrededor del 12\% del territo- 
Neoextractivismo, megaproyectos y conflictividad en Guatemala y Nicaragua

rio nacional. En este último año se registró la solicitud de 6785 kilómetros cuadrados para concesión, y existen más de 4000 kilómetros cuadrados de áreas protegidas otorgadas bajo el régimen de concesiones (Alvarez, 2013). El número de concesiones activas en minería metálica, básicamente oro y plata, asciende a cuarenta y ocho, además de registrarse ciento veintiséis inactivas.

En el 2007 la compañía británica Condor Gold Plc obtuvo una concesión de 250 kilómetros cuadrados por un periodo de veinticinco años en el área de la antigua mina La India, clausurada desde 1956. Los noventa trabajadores de esta compañía trabajan intensamente para perforar 25 metros todos los días una mina que será explotada a cielo abierto, proyectada para colocarse hacia 2017 en la tercera posición al producir 152000 onzas, más de la mitad de la producción programada por la industria minera del país, cuya cifra es de 297000 onzas (Álvarez, 2013).

Por su nivel de producción destacan tres minas: $L a$ libertad, que en 2010 logró producir 70000 onzas troy, con exportaciones con un valor de 87.2 millones de dólares; con menor producción están Homco y Limón, que juntas generaron 72 millones de dólares por concepto de exportación. La Libertad y Limón pertenecen a la canadiense B2GOLD; Hemco que se ubica en la Región Autónoma Atlántico Norte, es de capital tripartita (canadiense, estadounidense y colombiano ${ }^{2}$ ). El administrador de la mina La libertad declaró en 2011 lo siguiente: "tenemos reservas en este momento para siete años de operación continua y con eso tenemos un plan establecido de producción de 80000 y

2. Hasta abril de 2013 Nicaragua tenía acciones en esta empresa, pero en marzo de 2013 , el $90 \%$ de sus acciones fue vendido a la compañía colombiana Mineros, S.A. En 2012 Hemco se ubicó en el lugar siete entre las empresas que más exportaron, con 96.3 millones de dólares. Cuenta con 532 empleados y procesa diariamente 700 toneladas de material que contiene oro. 
90000 onzas anuales. Esto es lo que está asegurado ahorita en vida de la mina" (Navas, 2011).

En el año 2005 se exportaron 102400 onzas troy de oro y 96000 onzas troy de plata, con un valor sumado de 43.2 millones de dólares, que representaron $5 \%$ del valor de las exportaciones de mercancías. En el 2013, las exportaciones de oro se habían multiplicado por tres al sumar 309500 onzas troy, y las de plata 456600 onzas troy, casi cinco veces lo registrado en el 2005. En términos de valor, ambos metales sumaron 442.57 millones de dólares, 924\% con respecto al 2005, representando $18.4 \%$ del valor total de bienes exportados (Banco Central de Nicaragua, 2014). Las cifras reportadas por el Banco de Nicaragua, ${ }^{3}$ hasta el 2013, revelan que el oro se había convertido en el primer producto de exportación, con 431.6 millones de dólares, por arriba de las de carne y café que alcanzaron 383.8 y 349.5 millones de dólares, respectivamente.

La generación de energía para el capital frente a la producción de alimentos para la población

Junto con la minería, el capital ha venido impulsando la producción de agrocombustibles, en particular palma africana y caña de azúcar, por lo que en la década de 1990 Guatemala se volvió más dependiente de las importaciones agroalimentarias, incluso las hambrunas estacionales son cada vez más agudas. La apertura a las importaciones de alimentos provocó que muchos productores no pudieran competir con el maíz subsidiado de Estados Unidos, de manera que la producción per cápita cayó 30\% entre 1995 y 2005.

En consecuencia, las importaciones de este grano básico crecieron $221 \%$ entre 2002 y 2012 ; yendo de los casi 70 millo-

3. Consultado en: http://www.ben.gob.ni/estadisticas/anuario_estadistico/index. php

\section{6}


Neoextractivismo, megaproyectos y conflictividad en Guatemala y Nicaragua

nes de dólares en el primer año a los casi 224 millones en el segundo. Al cierre de 2013, se registró una leve caída (la suma casi alcanzó los 206 millones de dólares) como consecuencia de una baja relativa en los precios internacionales. Entre 2007 y 2012 se importaron 219482 toneladas de maíz blanco, 91\% proveniente de Estados Unidos. Durante este periodo las familias más pobres sufrieron las consecuencias del incremento de precios: de 245 dólares por tonelada en 2007 a 400 dólares en 2010 (Gobierno de Guatemala, 2013). Con preocupación, la FAO señala que "en la actualidad gran parte de los municipios más pobres de Guatemala dependen de la compra de maíz para su seguridad alimentaria" (Fuentes et ál., 2005: 4).

En el caso de Nicaragua la importación de alimentos creció 275\% durante el periodo 2003-2013. Destacan las importaciones de arroz, cuyo valor aumentó más de 1600\%, así como las de leche en polvo (204\%). La firma del Tratado de Libre Comercio con México y, sobre todo, con Estados Unidos, ha tenido gran impacto en la producción de alimentos; la agricultura ha sufrido un proceso de reconversión hacia cultivos orientados al mercado externo. En 1972 Nicaragua exportaba arroz, no había necesidad de importar; sin embargo, el arroz subsidiado de Estados Unidos ha hecho que los importadores se beneficien. En 2011 se importaron casi 132000 toneladas de este cereal, y en 2013 alrededor de 120 000; no obstante, mientras en el primer año se pagaron 49.3 millones de dólares, en el segundo la suma fue de 53.8 millones; es decir, el pago aumentó 9\%.

En el presente, el aceite de palma ocupa el tercer lugar dentro de la lista de productos de exportación agrícola más importantes de Guatemala, después del azúcar y el banano. Con el crecimiento de la frontera agrícola de estos cultivos, asistimos a un proceso de reconfiguración de nuevas territorialidades generadoras de vulnerabilidad humana. La historia del cultivo de la palma africana en Guatemala 
viene de los años ochenta del siglo pasado. Es, sin embargo, a partir del año 2000 cuando el cultivo comenzó a incrementar sostenidamente -y de manera exponencial en los últimos años de esta década-, "respondiendo al alza en los precios internacionales del aceite crudo de palma, motivada por su creciente demanda por la industria agroalimentaria, cosmética, y especialmente por la agroenergética" (Fradejas, Alonso y Dürr, 2008: 33).

De acuerdo con el Censo Agropecuario 2003, la superficie cultivada con palma africana sumaba en ese entonces 31000 hectáreas. Pero, con el vertiginoso aumento de 8000 hectáreas por año, en 2011 la frontera palmera se había extendido hasta llegar a 90000 hectáreas, y para el 2013, según cifras dadas a conocer en el marco del I Congreso Palmero Latinoamericano, ${ }^{4}$ habían ya 120000 hectáreas con una producción de 350000 toneladas, convirtiéndose en el cuarto productor en América Latina, después de Colombia, Ecuador y Honduras. ${ }^{5}$

El mercado y la crisis ambiental y energética que padecen los países centrales están induciendo a los países periféricos, mediante incentivo de precios y mecanismos institucionales, a la ampliación de la frontera agrícola en materia de agrocombustibles. En Centroamérica, desde el marco de la Estrategia Energética Sustentable 2020 (CEPAL, 2007), que establece como meta la sustitución del 15\% de derivadas del petróleo, y desde el Proyecto Mesoamérica, se viene impulsando el cultivo y la producción de aceite de palma africana. Poco se sabe sobre los avances del Programa Mesoameri-

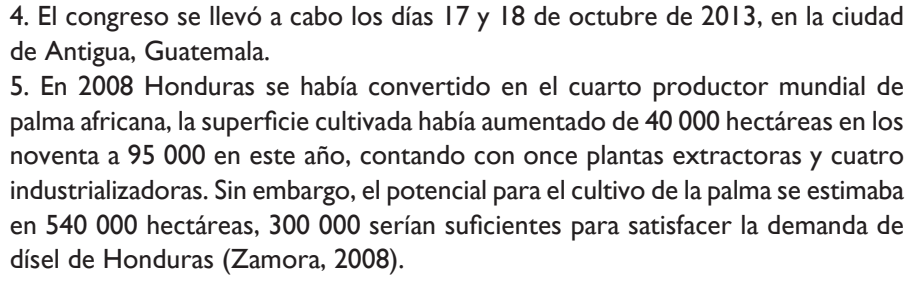
palma africana, la superficie cultivada había aumentado de 40000 hectáreas en los noventa a 95000 en este año, contando con once plantas extractoras y cuatro industrializadoras. Sin embargo, el potencial para el cultivo de la palma se estimaba en 540000 hectáreas, 300000 serían suficientes para satisfacer la demanda de dísel de Honduras (Zamora, 2008). 
Neoextractivismo, megaproyectos y conflictividad en Guatemala y Nicaragua

cano de Biocombustibles que se lleva a cabo en el marco del Proyecto Mesoamérica, con el liderazgo de Colombia y apoyo financiero del Banco Interamericano de Desarrollo. La información se guarda como secreto de Estado y lo poco que se filtra es información atrasada. Por ejemplo, en una de las hojas informativas más recientes se lee: "en mayo de 2012, el Banco Interamericano de Desarrollo (BID) aprobó una Cooperación Técnica No Reembolsable por un monto de 350 mil dólares, para apoyar técnica y financieramente la ejecución del Plan de Acción de la Red Mesoamericana de Investigación y Desarrollo en Biocombustibles (RMIDB) (Proyecto Mesoamérica, 2013).

Guatemala es el país que ha venido asumiendo con mayor celeridad el nuevo modelo extractivista. La producción de caña de azúcar -una fuente potencial para producir etanolha crecido a lo largo de los últimos años, de tal manera que entre 2000 y 2010, la frontera cañera ha pasado de las 179000 hectáreas a las 232000 (CEPAL, 2011). De hecho, Guatemala fue el único país que creció con tal celeridad: poco más de 5000 hectáreas por año. En el ciclo cañero 2012-2013 la superficie fue de 235000 hectáreas, y las exportaciones de azúcar ascendieron 1912426 toneladas métricas, lo cual colocó a Guatemala como el segundo exportador de América Latina y el Caribe y como el cuarto exportador mundial. Además, en ese mismo periodo, produjo 250 millones de litros de etanol, de los cuales $80 \%$ se destinaron a la exportación.

Aunque a menor ritmo, Nicaragua también ha venido avanzando en el cultivo de la palma africana. El presidente Bolaños alentaba en 2006 a los empresarios a invertir, argumentando que se trataba de la "oportunidad del futuro". En el marco de un encuentro con empresarios y diplomáticos en Managua, Bolaños señaló que en el municipio de Kukra Hill (Kukara, en la expresión de los habitantes del lugar) existen 6000 hectáreas cultivadas, no obstante la zona tiene 
capacidad para cultivar 120000 hectáreas: "Kukra Hill está dentro de un área superior a 2 millones de hectáreas que han sido deforestadas en los últimos cincuenta años, pero que afortunadamente presentan mejores condiciones agroecológicas para reforestar con palma africana" (IICA, 2006). Los suelos de esta zona son los más fértiles de la Región Autónoma del Atlántico Sur, la cual cuenta con un clima tropical con precipitaciones que oscilan entre 2000 y 3000 milímetros. Según el Ministerio Agropecuario y Forestal de Nicaragua, hoy existen en esta región carca de 16000 hectáreas cultivadas con palma africana. Además, en el Programa Nacional de Biocombustibles, se planteó, durante el gobierno de Enrique Bolaños, el cultivo de 200000 hectáreas de palma africana en tierras deforestadas del Atlántico.

El modelo neoextractivista incluye la construcción de hidroeléctricas, el desarrollo de proyectos de generación de energía eólica y producción de etanol derivado de la caña de azúcar. En este sentido, es importante señalar que Nicaragua ha liderado la producción de etanol, pues sus exportaciones llegaron a los 70 millones de litros en 2008. La generación de energía eólica muestra un avance considerable en los últimos años. Con la concesión del Consorcio Eólico Amayo Fase II, en 2013 -el cual generaría 37 megavatios de electricidad mediante dieciocho aerogeneradores-, sumados a la Fase I -que inició operaciones en la misma zona en 2009 y aporta 40 megavatios-, el país cuenta con el parque eólico más grande de Centroamérica. Por si no fuera poco, desde julio de 2012 opera en Rivas $L a$ Fe San Martín, de la compañía Blue Power \& Energy, con una generación de 39.9 megavatios. A la planta se suma Eolo de Nicaragua, de la compañía Globeleq Mesoamerica Energy, con capacidad para generar 44 megavatios. Y en total, se trata de tres parques (Amayo, Blue Power y Eolo) que pueden producir hasta el $22 \%$ de la energía que consume 
Neoextractivismo, megaproyectos y conflictividad en Guatemala y Nicaragua

Nicaragua. Finalmente, cabe señalar que la empresa Alba de Nicaragua, S.A., de capital venezolano-nicaragüense, ha iniciado la construcción de la primera fase de un parque eólico con capacidad para producir 40 megavatios (se requirió de una inversión de 90 millones de dólares). El conjunto de estos parques genera en total 200 megavatios, aunque se estima que el país tiene un potencial para producir 800 .

Un estudio de la CEPAL-SICA (2007) señala que Centroamérica cuenta con un potencial hidroeléctrico de 22000 MW, de los cuales únicamente se aprovecha $17 \%$. Tan solo Guatemala tiene un potencial de 5000 MW, y su capacidad instalada es de casi $13 \%$. Por su parte, Nicaragua cuenta con un potencial de 1760, y aprovecha solamente $5.9 \%$. El reporte más reciente de la CEPAL sobre el avance histórico del Proyecto Mesoamérica indica que en la región se registró un incremento neto de la capacidad instalada de $532 \mathrm{MW}$, correspondiendo $50 \%$ a hidroeléctricas, $35.1 \%$ a combustibles fósiles, $8 \%$ a geotermia, $4.1 \%$ a bagazo de caña en ingenios azucareros y $2.7 \%$ a viento (CEPAL, 2013).

Hace poco el gobierno de Guatemala, a través de la Comisión Nacional de Energía Eléctrica, publicó el plan de expansión de generación de energía eléctrica 2014-2028. En él se contempla la construcción de cuarenta y seis hidroeléctricas con una potencia que va de 10 a $181 \mathrm{MW}$-en estas no se incluye el proyecto Palo Viejo ${ }^{6}$ que está por entrar en operaciones comerciales-y se proyecta un escenario medio de demanda de 2975 MW hacia el último año referido, lo

6. Esta hidroeléctrica inició su construcción en 2009 y desde el 2012 comenzó hacer pruebas, pertenece a la empresa italiana Enel Green Power. En el 2011 (febrero-junio) paró sus actividades debido a que pobladores de la comunidad conde se ubica (San Juan Cotzal, departamento de Quiché) exigían regalías y construcción de caminos. En su página de Internet la empresa refiere: "la compañía cuenta actualmente con [...] 5 centrales hidroeléctricas en Baja Verapaz (Matanzas-San Isidro) y Quetzaltenango (El Canadá-Monte Cristo), con una capacidad instalada de $163 \mathrm{MW}$ enteramente del hidroeléctrico" (http://www. enelgreenpower.com/es-ES/company/worldwide/guatemala/). 
cual es un incremento de 78.5\%, en relación con el año 2013 y considerando que en este año la demanda había sido de 1666 MW (Ministerio de Energía y Minas, 2014).

Bajo las directrices de la CEPAL, el espíritu del Proyecto Mesoamérica, con el apoyo del Banco Interamericano de Desarrollo y la Agencia Internacional de Desarrollo de los Estados Unidos de América del Norte, la producción energética avanza en la región. El proyecto SIEPAC representó un paso significativo para generar un mercado de energía en la región, y está dando resultado. En todos los países son visibles los proyectos de construcción de hidroeléctricas. Tal situación ha dado origen al Frente Guatemalteco contra las Represas, en 2005, y en 2006, al nicaragüense Movimiento Multisectorial contra la Represa hidroeléctrica Copalar, megaproyecto hidroeléctrico Río Grande de Matagalpa, conocido como Copalar, el cual contempla generar hasta 980 MW mediante la construcción de tres presas (Copalar, Tumarín y Mojolka) con un costo de 1200 millones de dólares. De este último se prevé que inundaría al menos 345 $\mathrm{km}^{2}$ e implicaría el desalojo de 40000 personas.

En resumen, los estudios sugieren que el área centroamericana está llamada a contribuir significativamente con la producción energética y con el proceso de integración energética que beneficiará a las empresas involucradas en el negocio de los energéticos. La cabeza más visible son las empresas españolas, en particular Unión Fenosa, pero también es relevante la participación de inversionistas de Estados Unidos, Taiwán, Corea, Costa Rica y Honduras.

\section{La migración como actividad extractiva}

Una de las expresiones del neoextractivismo es la migración, en especial la migración internacional, que se ha convertido en una fuente estratégica de divisas para los países centroamericanos, en particular para Nicaragua y Guatemala. En 2013, en ambos países se registraron cifras históricas de 
Neoextractivismo, megaproyectos y conflictividad en Guatemala y Nicaragua

remesas. Para Nicaragua el monto ascendió a 1078 millones de dólares, que significó el 45\% del valor de las exportaciones de bienes y por arriba de la suma de las exportaciones de oro, plata y café, las cuales alcanzaron los 792.1 millones de dólares. En el caso de Guatemala, las remesas rebasaron los 5105 millones de dólares; cantidad que representó el 50.2\% del valor de las exportaciones de bienes, y se colocaron por arriba del valor de las exportaciones de los cinco principales rubros: artículos de vestuario, azúcar, café, banano y minería, que juntos sumaron 4033 millones de dólares.

Las grandes sumas de dinero generadas por el trabajo clandestino, que las propias economías no han sido capaces de crear, forman parte del modelo extractivista neoliberal, en tanto que este es también una expresión del despojo. Un despojo conseguido a través de políticas que favorecen el capital, concentran la tierra en pocos propietarios y no generan suficientes empleos; de manera que en ausencia de opciones de una inserción laboral digna, no queda otro camino que desplazarse. Así, la migración laboral irregular forma parte de esta nueva era del extractivismo, modelo que avanza conforme van siendo rentables actividades como la producción de agrocombustibles, la minería y la generación de energía eléctrica.

Los estudios sobre el neoextractivismo no han reparado en el hecho de que la migración y las remesas forman parte del modelo. Con todo, si seguimos el análisis que Marx (1975 [1894]) ofrece sobre la acumulación originaria de capital -la cual pondera el florecimiento de las manufacturas laneras y la consiguiente alza de precios como acicate para los abusos y el despojo-, encontraremos que la situación descrita por el autor es muy similar al actual neoextractivismo, actualmente responsable de arruinar varios países -Centroamérica no es la excepción-. En el neoextractivismo las mineras, alentadas por los buenos precios, están comprando tierras en asentamientos campesinos con altos niveles de 
pobreza; compras que a primera vista aparecen como un negocio exitoso para el que vende la tierra, sin saber que en el subsuelo se encuentran yacimientos de metales que harán más ricas a las empresas y terminarán orillando a la población nativa a emigrar. De igual forma ocurre con los agrocombustibles y la construcción de presas hidroeléctricas, que convierten las tierras para producir alimentos en espacios para la producción de energía metabolizada por el capital. El raudo metabolismo del capital devora todo lo que posibilita su crecimiento, sin importar el costo social y ambiental de su incesante engullir. Se trata de una carrera frenética que está generando violencia y desintegración en muchas comunidades. Las transformaciones del territorio se expresan, entre otras cosas, en el desplazamiento de grandes masas de población que pasan a engrosar las corrientes migratorias, en el caso de Nicaragua, fundamentalmente a Costa Rica, y en el Caso de Guatemala, preponderantemente a los Estados Unidos.

\section{La guerra canalera: megaproyectos para dinamizar el nuevo modelo extractivo}

A tono con el modelo económico neoextractivista, y en lo que parece una "guerra canalera", a la par de la ampliación del Canal de Panamá, en Nicaragua y Guatemala se proyecta la construcción de dos megaproyectos que permitirían la reinserción de la región centroamericana, y de estos dos países en particular, en la dinámica del comercio mundial. Se trata de la construcción de dos canales o corredores interoceánicos, cuya viabilidad ha desatado un fuerte debate.

En el caso de Nicaragua, desde finales de 1999, durante la administración del presidente Arnoldo Alemán se integró una comisión de trabajo. Luego, en 2006 el gobierno de Enrique Bolaños lanzó la propuesta en el documento denominado "Perfil del proyecto. Gran canal interoceánico 
Neoextractivismo, megaproyectos y conflictividad en Guatemala y Nicaragua

por Nicaragua”. En las primeras líneas del referido escrito, el proyecto es planteado en los siguientes términos:

El proyecto del Gran Canal Interoceánico por Nicaragua (el Gran Canal o el Proyecto), con un costo de inversión de unos 18,000 millones de dólares de 2006, consiste en unir a los océanos Atlántico y Pacífico por medio de un canal acuático. Tiene dos componentes; a) infraestructura, incluyendo estudios, diseño, financiamiento, construcción y operación de un canal interoceánico con capacidad para grandes buques de hasta 250,000 toneladas de peso muerto y longitud de 286 kilómetros, incluyendo 80 km en el largo; y b) restauración, preservación y desarrollo del medio ambiente en la zona de influencia del Gran Canal en el país (Comisión de Trabajo del Gran Canal, 2006: II).

El citado documento plantea que el proyecto podría desarrollarse en unos once años a partir de una ley especial. "El Gran Canal, se estima, captaría unos 416 millones y 573 millones de toneladas métricas en 2019 y 2025, respectivamente $(3.9 \%$ y $4.5 \%$ de la carga marítima mundial o alrededor de $46 \%$ de la demanda potencial o relevante)" (Comisión de Trabajo del Gran Canal, 2006: 12).

En la justificación se plantea que la capacidad de carga del Canal de Panamá está suturada. Mueve unas 200 millones de toneladas métricas, $2 \%$ de la carga marítima mundial y un tercio de la carga del mercado potencial. Con la ampliación, el canal podría permitir el tránsito de buques de hasta 120000 o 130000 toneladas de peso muerto, así como buques portacontenedores de hasta unos 10500 de 20 pies de largo (TEU, por sus siglas en inglés). Sin embargo, en el documento referido se argumenta que "la tendencia de la industria naviera es la construcción y operación de buques entre 150,000 y 250,000 toneladas de peso muerto y portacontenedores de más de 10,500 TEU, para lograr economías de escala buscando mayor eficiencia operativa y rentabilidad" (Comisión de Trabajo del Gran Canal, 2006: 13).

Estado 8 No.61 
En el perfil del proyecto del Gran Canal se ponen de relieve los grandes beneficios que generaría para Nicaragua: desarrollo ambiental y crecimiento del PIB en más de $300 \%$, lo cual en otras palabras significa que pasaría de los cerca de 5000 millones de dólares estimados en 2005 a los casi 21000 millones en 2025, mientras que el PIB per cápita crecería 163\%, pasando de 857 a 2258 dólares en el mismo periodo; un incremento que sin el canal tan solo alcanzaría los 1285 dólares. Entre los beneficios estimados se señala la generación de 40000 nuevos empleos directos durante la construcción y 20000 durante la operación, más otros ciento veinte empleos indirectos. Todo lo anterior tendría un efecto de arrastre en los ramos de la educción, la inversión, el turismo, la infraestructura, la comunicación y el comercio con los grandes bloques comerciales de la región AsiaPacífico, el MERCOSUR, el NAFTA y la Comunidad Europea; en una palabra, en el desarrollo del país. Esta es la visión del gobierno de Nicaragua; como se ve, dentro de la lógica del capitalismo globalizador y destructor de la naturaleza.

Años después de la elaboración del documento, en junio de 2012, se promulgó la ley 800 o "Ley del Régimen Jurídico de el Gran Canal Interoceánico de Nicaragua" (Gaceta Diario Oficial, 2012), que declara ser de prioridad e interés supremo nacional el Gran Canal. Un año después, se aprobó la ley 840 o "Ley Especial para el Desarrollo de Infraestructura y Transporte nicaragüense atingente a El Canal, zonas de libre comercio e infraestructuras asociadas", que en su artículo primero refiere que la citada ley tiene como finalidad aprobar, y posteriormente autorizar a firmar, el Acuerdo Marco de Concesión e Implementación, el cual ha de suscribirse entre la autoridad de el Gran Canal Interoceánico de Nicaragua, la Empresa desarrolladora de Grandes Infraestructuras, S.A., y HK Nicaragua Canal Development Investment Co. Limited (HKC), una compa- 
Neoextractivismo, megaproyectos y conflictividad en Guatemala y Nicaragua

ñía de responsabilidad limitada construida en Hong Kong (Gaceta Diario Oficial, 2013a).

Las reacciones a esta ley 840 no se hicieron esperar, y la mayoría de los comentarios realizados a través de la prensa señalaron la violación de la constitución nicaragüense dada la configuración de la empresa desarrolladora, pues El inversionista es una empresa representada por la HKNC Group Honding Limited, ${ }^{7}$ la cual es una entidad matriz de la misma que está constituida según las leyes de las Islas Caimán, es dueña del $100 \%$ de sus acciones y está personificada en la figura del empresario chino Wang Jing. ${ }^{8}$ Además, el acuerdo otorga la concesión del Gran Canal a esta empresa por cincuenta años y es renovable por cincuenta más. Para algunos opositores al régimen de Daniel Ortega, el asunto del Gran Canal es de carácter electorero, en perspectiva de lograr cambios constitucionales que permitan la reelección de Ortega en 2016, cuestión que se logró el pasado 28 de enero de 2014 con sesenta y cuatro votos a favor y veinticinco en contra. Para otros, el Gran Canal simplemente carece de viabilidad económica porque se requiere de mucho dinero. De hecho, la oposición no proviene de sectores populares, sino de sectores políticos opositores del régimen de Ortega. Es más, en enero de 2014, el dirigente de la Confederación Sindical de Trabajadores José Benito Escobar, que aglutina doscientos sindicatos, expresó que estarían disponibles unos

7. Según el Acuerdo Marco de Concesión e Implementación del Canal de Nicaragua, publicado en La Gaceta-Diario Oficial de fecha 17 de junio de 2013, la HKND Group Holdings Limited es una compañía exenta y de responsabilidad limitada constituida por HKC en las Islas Caimán el 7 de noviembre de 2012 para ser una HoldCo contemplada en la escritura de Cooperación.

8. Los medios han investigado el perfil de este empresario y lo que se sabe es que se trata de una persona de cuarenta y un años, nacido en Beijing, que tiene inversiones en minas y telecomunicaciones, es presidente y accionista de la compañía china Xinwi Telecom Technology Co., con una participación de II 00 millones de dólares. El portal de noticias de China, Tencent Finance, refirió: "Un empresario secreto tiene la oportunidad de cambiar el destino de uno de los países más pobres de América, Nicaragua. En sus manos tiene la posibilidad de cambiar el comercio mundial", citado por Romero y Martínez (2013). 
doscientos mil trabajadores para las obras del Gran Canal (La Prensa, Nicaragua, 2014).

Paralelamente a las actividades realizadas en vistas de la construcción del Gran Canal en Nicaragua, en Guatemala se ha hecho público el interés del gobierno por la construcción de un canal seco interoceánico. Los propósitos, de acuerdo con la promotora de la obra son: 1) ser un instrumento de desarrollo para Guatemala, 2) fortalecer la integración económica centroamericana, y 3) promover un cambio en la cultura corporativa del país y la región con responsabilidad social y ambiental.

La idea no es nueva: desde 1980 se estableció la Oficina de Enlace y Negocios para América Latina (ODEPAL), y en el año 1999, con la idea de la construcción de la obra, esta oficina se constituyó como sociedad mercantil, registrada desde 2001 con el nombre Oficina de Enlace y Negocios para América Latina Sociedad Anónima, también conocida como ODEPAL INTERNACIONAL. Según se puede leer en su página (http://odepal.net/), desde este año trabaja en la promoción y desarrollo del denominado "Corredor Interoceánico de Guatemala”. Un aspecto destacable en esta propuesta, a diferencia del Gran Canal de Nicaragua, es su estrategia, que, según sus promotores, es una "alianza público-privado desde lo local”, que, con el lema Asociación Poder para Todos, incluye a cincuenta y ocho municipios, los cuales quedan organizados en diez mancomunidades, en las que se encuentran tres mil quinientos treinta y tres propietarios y asociaciones comunitarias.

La sociedad promotora del proyecto reconoce la existencia del riesgo, sobre todo, por la falta de antecedentes de este tipo de iniciativas en el continente americano. Sin embargo, su idea es minimizarlos, por un lado, invitando a distintas empresas de prestigio nacional e internacional a aportar su experiencia y, por el otro, a través de estudios jurídicos, de prefactibilidad, de mercado y de impacto ambiental y social. 
Neoextractivismo, megaproyectos y conflictividad en Guatemala y Nicaragua

¿En qué consiste este proyecto? La ambiciosa propuesta de obra cuya maduración ha sido lenta pero firme, es competir con el Canal de Panamá. A mediados del 2013 se publicó el Acuerdo Gubernativo 270-2013. En él se declara al Corredor Interoceánico de utilidad pública e interés nacional. Incluso, en una visita realizada por el presidente de Guatemala a Taiwán, en julio de 2013, el mandatario precisó que la construcción del corredor está en pie: "el plan y los estudios están mucho más avanzados. Ya están los estudios completos y los derechos de vía, y las autoridades locales por donde pasará están de acuerdo y lo apoyan, lo que facilita su rápida viabilidad" (Prensa Libre, 2013).

La revista Construcción Internacional, en su edición enero-febrero 2014, señala los componentes del proyecto de 10000 millones de dólares: 1) construcción de dos nuevos puertos: San Luis, en el Pacífico, y San Jorge en el Atlántico, con capacidad de 7.6 millones de TEU cada uno, los cuales permitirán el atraque de buques de hasta 22000 TEU de capacidad; 2) plataformas aledañas a los puertos de 1736 hectáreas para el desarrollo de parques industriales y agroindustriales; 3) 372 kilómetros de conexión ferroviaria de doble vía que uniría a las costas del Atlántico y del Pacífico, y haría posible el paso de contenedores, automóviles y trenes de pasajeros con estaciones a lo largo de la vía; 4) corredor de energía, el cual consiste en sistemas independientes de bombeo de crudo, derivados del petróleo y gas; 5) zonas de multiactividad con reservas de paso de red eléctrica, agua y fibra óptica (Peters, 2014). Según el gobierno y los impulsores del proyecto, el Corredor Interoceánico generará beneficios al sureste de México, Belice, Guatemala, Honduras y El Salvador. Será una ruta corta para el comercio entre Asia y los principales mercados de la costa este de Estados Unidos, y entre esta y los países de cara al Atlántico de América Latina y Europa. 
Sin embargo, a pesar de todos los beneficios que promete el proyecto, hay voces inconformes, por lo pronto, las del partido Unidad Nacional de la Esperanza (UNE); partido que presentó un recurso de inconstitucionalidad en contra del acuerdo gubernativo 270-2013, por considerar que el proyecto compromete el espacio marítimo entre ríos y lagos, y afectará bienes públicos y privados. Por su parte, el Consejo Latinoamericano de Iglesias, que reúne ciento ochenta iglesias evangélicas, protestantes y luteranas de veinte países, se ha manifestado en contra de la construcción del corredor, ya que considera que no traerá ningún desarrollo a las comunidades campesinas del país (Arrazola, 2013).

\section{Memorial de conflictos}

En todas partes, y Nicaragua no es la excepción, el establecimiento del modelo neoextractivista, en particular el ejecutado por las mineras, siempre ha generado conflictos. Su estrategia es dividir a la población mediante la compra de tierras a los propietarios y el ofrecimiento de una cartera de proyectos sociales, incluyendo empleos, a los trabajadores. Ese fue el caso en la comunidad Santo Domingo, municipio de chontales que cuenta con una arraigada tradición de minería artesanal de más de cien años, y que se ha visto amenazada por la presencia de la empresa B2GOLD.

La conflictividad mayor se observa en Guatemala, donde el gobierno ha llegado a imponer el estado de sitio para reprimir el movimiento social opuesto a la industria minera. Las empresas más emblemáticas, por la violencia que han generado, son la mina de oro Marlin, ${ }^{9}$ ubicada en su mayor

9. "El proyecto Marlin consiste de una concesión de explotación de 20 kilómetros cuadrados (Marlin I), concedida en noviembre de 2003, y de otra concesión de exploración (Marlin II) concedida en enero de 2004. El 85\% de la concesión de explotación está ubicada en San Miguel Ixtahuacán y el 15\% en Sipacapa" (Van Sandt, 2009: 19). 
Neoextractivismo, megaproyectos y conflictividad en Guatemala y Nicaragua

parte en el municipio de San Miguel Ixtahuacán, departamento de San Marcos, frontera con México, y la de plata Tahoe Resources, en el municipio de San Rafael las Flores, departamento de Santa Rosa; ambas, de capital canadiense. Revisemos algunos ejemplos recientes.

La historia del conflicto en torno a la mina Marlin se inicia en 2005, con un bloqueo que duró cuarenta días, en el cual manifestantes y fuerzas de seguridad estatales se enfrentaron, y donde murió una persona y diez fueron heridas. Dos meses después, un miembro de la comunidad fue asesinado a manos de un empleado de seguridad. Con estos hechos, la oposición de las comunidades afectadas por la mina fue creciendo hasta convertirse en una bandera de lucha más amplia:

En junio de 2005, trece comunidades en Sipacapa llevaron a cabo una consulta popular con el objeto de decidir si permitirían o no la construcción de la mina en su territorio: once comunidades votaron en contra de la construcción de la mina, una votó a favor y una se abstuvo. Sin embargo, a pesar del rechazo mayoritario por parte de las comunidades, y sin tomar alguna acción para remediar los problemas identificados en los varios reportes, en diciembre de ese mismo año Goldcorp inició sus operaciones en la mina (AIDA, 20II).

Las protestas se han venido extendiendo a lo largo de los últimos años, al grado de que en 2008 los socios de Goldcorp pidieron a la corporación hacer una evaluación externa sobre los impactos del proyecto minero. Los conflictos tuvieron resonancia internacional, a tal punto que provocaron la intervención de la Comisión Interamericana de Derechos Humanos y del Relator Especial de la Naciones Unidas sobre Pueblos Indígenas.

A finales de junio de 2013, más de quinientos pobladores retuvieron a unos treinta y cinco trabajadores de la mina Marlin con el propósito de presionar a la empresa para que 
restituyera el abastecimiento de agua, porque, según los pobladores, a causa de la presencia de la minera se secaron los manantiales. Los vecinos argumentaron que la mina extrae grandes cantidades de agua mediante pozos mecánicos, los cuales son abastecidos por venas de nacimientos que han dejado de ser suficientes, provocando así el desecamiento de dichos pozos. ${ }^{10}$ Un vecino inconforme exigió: "queremos que las autoridades del Gobierno nos ayuden a solucionar el problema, porque esto es cosa seria" (Prensa Libre, 2013c). Con todo, la ambición por las ganancias que proporciona el oro ha importado más que la salud de la comunidad y la del medio ambiente: la empresa sigue con su plan extractivo.

En torno a la mina San Rafael los conflictos comenzaron en 2007 con la llegada de la compañía canadiense Goldcorp Inc. Años más tarde, en 2010, la mina fue vendida a la Tahoe Resources, y las tensiones aumentaron, porque la mayoría de los pobladores no estaba de acuerdo con la actividad de la minera. Las protestas se intensificaron al punto que la explotación tuvo que ser resguardada por efectivos del ejército. El 17 de septiembre de 2012 trabajadores de la mina fueron interceptados y retenidos por los pobladores que se oponen a esta. Al día siguiente, un grupo de desconocidos incendio depósitos de las minas y a un patrullero. En noviembre del mismo año, habitantes del municipio quemaron un hotel y sustrajeron dinamita de la mina cuando las autoridades impidieron una reunión en el pueblo de Mataquescuintla, donde se llevaría una reunión para hablar al respecto. El 11 de enero de 2013 se produjo un tiroteo entre manifestantes y personal de seguridad de la mina, que cobró la vida de un agricultor y dos guardias.

10. "La mina Marlin consume un promedio de 45,000 litros de agua por hora ( $12.5 \mathrm{~L}$ por segundo) proveniente de pozos de agua dulce, mientras $47 \%$ de las familias de la zona no tienen acceso a fuentes de agua fuera de los ríos, quebradas y pozos" (AIDA, 20II). 
Neoextractivismo, megaproyectos y conflictividad en Guatemala y Nicaragua

El 17 de marzo del año referido, un grupo armado secuestró a cuatro miembros del parlamento xinka en la aldea Pino Dulce, municipio de Mataquescuintla; uno de ellos apareció muerto.

La violencia ha venido subiendo desde 2012, llegando a su clímax el 27 de abril de 2013, con el atentado armado contra ocho comunitarios (luego se produjo la captura del jefe de seguridad de la mina). Esto obligó al gobierno a ordenar el 2 de mayo de 2013 la implementación del estado de sitio mediante el Acuerdo Gubernativo 06-2013, en cuatro municipios: Mataquescuintla, y la cabecera de Jalapa, Casillas y San Rafael las Flores. Para tal efecto se desplegaron tres mil quinientos militares y policías, con fuerzas motorizadas del ejército y fuerzas especiales antidisturbios de la policía nacional civil, equipadas con radio patrullas, camiones, unidades artilladas y tanquetas.

A grandes líneas, el lector notará que es un conflicto entre dos visiones del desarrollo: por una parte, la del modelo neoliberal, la cual se expresa en el proyecto extractivista ejercido por el capital canadiense con el apoyo del Estado guatemalteco a través de la Ley Minera de 1977 y del Decreto Gubernativo 499 de 2007 que incentiva la minería y, por la otra, la del desarrollo basado en las identidades locales que se oponen a la explotación minera y a la construcción de hidroeléctricas.

Hasta ahora, los proyectos mineros no se han detenido y, sin embargo, el movimiento social en contra de la minería en Guatemala ha provocado que el gobierno piense en salidas para evitar el crecimiento de la protesta social. Desde el 2012 se han estado impulsando reformas a la Ley Minera de 1997 que permite la obtención de rentas extraordinarias a las compañías, obligándolas a pagar únicamente el 1\% por concepto de regalías, incluyendo la obtención de la propiedad total de las tierras por la empresa. Con el propósito de frenar la protesta social, el 28 de enero de 2012 se firmó 
un convenio de regalías voluntarias, para pasar del 1 al 5\% mientras se alcanza un acuerdo entre los partidos para la aprobación de las reformas. En este marco, el 30 de enero de 2014 la Minera San Rafael entregó a las autoridades del municipio la cantidad de 12.5 millones de quetzales por concepto de regalías voluntarias, correspondiente al periodo octubre-noviembre de 2013, cuando la empresa exportó concentrados de plomo y zinc por un valor de 248 millones de quetzales, equivalentes a un millón de dólares. El gesto de la empresa la convierte en representante del "capital con rostro humano". Durante la ceremonia donde se entregó el dinero, el alcalde de San Rafael expresó: "espero que otros municipios abran las puertas, porque la minería controlada en Guatemala puede erradicar la pobreza" (Ministerio de Energía y Minas, 2014).

No obstante, los conflictos no se originaron meramente por los proyectos mineros, se deben también a la construcción de presas para la generación de energía eléctrica y, en menor medida, están contra la expansión de la palma africana, particularmente en Guatemala, donde el cultivo está provocando una reconcentración de la tierra en varios departamentos, sobre todo en las zonas del alto potencial como Petén, Alta Verapaz, Zacapa e Izabal. En Barrillas, el departamento fronterizo de Huehuetenango, desde 2011 los pobladores se oponen a que la empresa Hidro Santa Cruz, de capital español, construya una presa. En la localidad, la violencia alcanzó su nivel más álgido a principios de mayo de 2012, cuando el gobierno decretó el estado de sitio y envió cuatrocientos policías y quinientos militares.

\section{Reflexión final: el imaginario canalero}

La globalización neoliberal y el incremento en el precio de los commodities durante la última década han hecho que resurjan los viejos sueños canaleros. Hemos destacado los 
Neoextractivismo, megaproyectos y conflictividad en Guatemala y Nicaragua

proyectos de Nicaragua y Guatemala, pero también están los Honduras y México. Respecto al último, recuérdese el tantas veces pospuesto proyecto del Istmo de Tehuantepec, contemplado soterradamente en el Plan Puebla Panamá, y que hoy día, con las reformas neoliberales de última generación, está de nuevo en la agenda del gobierno del presidente Peña Nieto. Sobre Honduras, cabe señalar que en septiembre de 2012 el ministro de Obras Públicas anunció un proyecto de canal seco de 280 kilómetros de largo, el cual atravesaría el país desde puerto Cortés, en el Atlántico, hasta el Golfo de Fonseca, en el Pacífico, con una inversión de 5500 millones de dólares. Pero a casi dos años de la noticia, prácticamente no existe información. Es poco creíble que un país convulsionado por la crisis económica, donde la pobreza afecta al 70\% de su población y la violencia es acrecentada por la presencia del narcotráfico, y que además tiene un millón de desempleados y una deuda externa cercana al $30 \%$ de su PIB, pueda concebir un proyecto de esta envergadura.

Hasta la fecha predomina el escepticismo sobre los proyectos canaleros en la conflictiva Centroamérica, particularmente en Guatemala y Honduras, pero también en Nicaragua, país con menos protesta social, pero con menos posibilidad financiera. ${ }^{11}$ Así y todo, en el imaginario de los gobiernos centroamericanos los proyectos están más que nunca vigentes: todos apoyan sus planes en el argumento de la limitada capacidad del Canal de Panamá frente a la creciente demanda. Y no obstante las dificultades por el incremento de los costos que ha venido enfrentando la ampliación del Canal de Panamá, y que pone en riesgo su conclusión en el 2015, como se había planeado original-

II. También porque aún no se sabe sobre la solvencia del concesionario chino ni cómo financiará este la obra. Aunque últimamente Rusia ha manifestado interés. 
mente, la obra sigue avanzando; de manera que en el peor de los escenario la obra quedaría concluida en el $2020 .{ }^{12}$

La pregunta es si seguiría siendo atractivo invertir en proyectos de dudosa realización por su rentabilidad y por la enorme conflictividad estructural que enfrentan los países centroamericanos. Es cierto que, como hemos apuntado, Centroamérica se enfila hacia la profundización de un modelo económico neoextractivista, pero también hay que reconocer la conflictividad y violencia desatada en torno a los proyectos más destructivos, como la minería y las hidroeléctricas, que en el caso de Guatemala ha llevado al gobierno a decretar un estado de sitio.

Pero mientras los sueños canaleros se siguen alimentando, el modelo neoextractivista continúa avanzando pese a la oposición de grupos de la sociedad civil. El neoextractivismo cuenta ahora con ventajas tecnológicas que hace que la magnitud e intensidad de la explotación de los recursos naturales, y consecuente daño ambiental, sean incomparablemente mayores que en otra época: los agrocombustibles requieren de cantidades industriales de agroquímicos, contaminando así las tierras y el agua con más velocidad; los ríos se agotan y se contaminan con celeridad; los recursos mineros, con el uso de maquinaria pesada, pueden ser

\footnotetext{
12. En 2009 el consorcio GUPC (Grupo Unidos por el Canal) -en el que participan la empresa española Sacyr, la italiana Salini Impregilio, la belga Jan de Nul y la Panameña CUSA - ganó la licitación para la ampliación del Canal de Panamá con un costo de 3118 millones dólares, de los cuales se ha desembolsado hasta finales de 2013 un monto de 283 I millones de dólares. Sin embargo, el 30 de diciembre de 2013 el consorcio informó a la Autoridad del Canal de Panamá que si no recibían un pago adicional de 1600 millones de dólares hasta el 20 de enero de 2014 se suspenderían las obras. La Autoridad no aceptó el ultimátum del consorcio y refirió aun en el escenario de que el consorcio desistiera del contrato, la construcción de la obra estaba garantizada por medio de un seguro internacional con un valor de 600 millones de dólares. El avance de la obra es hasta el momento del $70 \%$, pero si se detiene la construcción podrá concluirse cinco años más tarde de lo previsto, en el 2020, una obra estratégica, sobre todo para Estados Unidos que permitirá el tránsito de buques con capacidad para trasportar 12000 contenedores, en lugar de los 4000 que transportan los buques de ahora.
}

\section{6}


Neoextractivismo, megaproyectos y conflictividad en Guatemala y Nicaragua

agotados en el corto y mediano plazo: un panorama inimaginable en los tiempos de la Colonia. Los gobiernos están decididos a seguir apoyando a las compañías mineras, a pesar de las protestas y las recomendaciones de los organismos internacionales; ${ }^{13}$ queda implícito que la destrucción del medio ambiente y la vida humana son irrelevantes si se los coloca al lado de las ganancias del oro.

Fecha de recepción: 18 de junio de 2014

Fecha de aceptación: 27 de junio de 2014

AIDA (Asociación Interamericana para la Defensa del Ambiente), 20II, Impactos humanos y sociales. La mina Mariln, Guatemala, en línea: http://www.aidaamericas.org/sites/default/files/MARLIN\%20MINE\%20 SPANISH\%20FINAL\%20 I I-05-27\%20LN.pdf

Alimonada, Héctor (coord.), 20 I I, La naturaleza colonizada. Ecología política y minería en América Latina, CLACSOCICCUS Ediciones, Buenos Aires.

Alfonso Fradejas, Alberto, Alonso, Fernando y Jochen Dürr, 2008, Caña de azúcar y palma africana: combustibles para un nuevo ciclo de acumulación y dominio en Guatemala, Instituto de Estudios Agrarios y Rurales-Coordinación de ONG y Cooperativas, Guatemala.

Alvarez, Rezaye, 2013, “Áreas de minería crecen rápido”, La Prensa, I I de diciembre, en línea: http://www.laprensa. com.ni/2013/I2/II/ambito/I73932-reas-mineriacrecen-rapido

Bibliografía

13. Recuérdese que la Corte Interamericana de Derechos Humanos propuso la cancelación de los trabajos de la mina Marlin en Guatemala. 
Daniel Villafuerte Solís

Bibliografía
Álvarez, Wendy, 2013, "Fiebre de oro en mina La India”, La Prensa, I 3 de agosto, en línea: http://www.laprensa.com. ni/2013/08/I3/portada/ I58329-fiebre-oro-mina-india

Arrazola, Carlos, 20I3, "Guatemala se alista para competir por el Canal de Panamá”, en La Prensa, 3 de agosto.

Banco Central de Nicaragua, 20I4, Estadísticas de comercio exterior, en línea: http://www.bcn.gob.ni/estadisticas/ sector_externo/balanza_pagos/index.php

Banco de Guatemala, 20I4, Flujo de IED por país de procedencia y actividad económica, en línea: http://www. banguat.gob.gt/inc/ver.asp?id=/Publica/v_man_bpagos/ flujo_IED_2007_2013.htm\&e=109199

CEPAL, 20II, Subregión norte de América Latina y el Caribe: información del sector agropecuario, 2000-2010, Sede subregional en México.

—, 2013, Mesoamérica: datos de integración económica intrarregional y reseña histórica del Mecanismo de Tuxtla, en línea: http://www.proyectomesoamerica.org/

CEPAL-SICA, 2007, Estrategia energética sustentable centroamericana, México.

Comisión de Trabajo del Gran Canal, 2006, Perfil del Proyecto del Gran Canal Interoceánico por Nicaragua, Gobierno de Nicaragua.

Composto, Claudia, 2012, “Acumulación por despojo y neoextractivismo en América Latina. Una reflexión crítica acerca del Estado y los movimientos socio-ambientales en el nuevo siglo”, Astrolabio, núm. 8, nueva época.

Dirección General de Minería, 2013, Anuario Estadístico Minero 2012, Ministerio de Energía y Minas, Gobierno de Guatemala.

Gaceta Diario Oficial, “Ley del Régimen Jurídico de el Gran Canal Interoceánico de Nicaragua y de creación de autoridad de el Gran Canal Interoceánico de Nicaragua” en Gaceta Diario Oficial, núm. 128. 
Neoextractivismo, megaproyectos y conflictividad en Guatemala y Nicaragua

Gaceta Diario Oficial, “Ley No. 840. Ley Especial para Bibliografía el Desarrollo de Infraestructura y Transporte Nicaragüense Atingente a El Canal, Zonas de Libre Comercio e Infraestructura Asociadas", en Gaceta Diario Oficial, núm. II 0.

—_, "Acuerdo Marco de Concesión e Implementación con relación a El Canal de Nicaragua y Proyecto de Desarrollo", en Gaceta Diario Oficial, núm. I I I.

Gobierno de Guatemala, 20I3, Informe de la situación del maíz blanco para Guatemala, Ministerio de Agricultura, Ganadería y Alimentación.

Gudynas, Eduardo, 2012, "Estado compensador y nuevos extractivismos. Las ambivalencias del progresismo sudamericano", Nueva Sociedad, núm. 237, enerofebrero.

IICA (Instituto Interamericano de Ciencias Agrícolas), 2006, "Empresarios a la espera de la legislación para invertir en agroindustria de biodiesel”, Boletín de Noticias del IICA, núm. I7I, en línea: http:// webiica.iica.ac.cr/prensa/boletines/nicaragua/default. asp? boletin=Boletin I 59\&num = I59

"200 mil trabajadores estarían disponibles para canal interoceánico en Nicaragua”, 20I4, La Prensa, 30 de enero.

Marx, Carlos, 1975 [1894], El capital. Crítica de la economía política, Fondo de Cultura Económica, México.

Ministerio de Energía y Minas, 2004, Caracterización de la minería en Guatemala. Primer Foro Nacional de la Minería en Guatemala, Dirección General de Minería, Gobierno de Guatemala.

__, 2006, Anuario Estadístico minero 2005, Departamento de Desarrollo, Gobierno de Guatemala.

_- 2014, Primera entrega de regalías voluntarias rebasa los q 12 millones. La comuna de San Rafael La Flores recibirá la mitad del presupuesto anual en poco menos 
Bibliografía $\quad$ de tres meses de operación minera, Gobierno de Guatemala, en línea: http://www.mem.gob.gt/20I4/0I/ primera-entrega-de-regalias-voluntarias-rebasa-losq I2-millones/

- 2014, Plan de Expansión Indicativo del Sistema de Generación 2014-2028, Gobierno de Guatemala, en línea: http://www.cnee.gob.gt/PlanesExpansion/PlanesExpansion20l4.html

Navas, Lucía, 20I I, "Fiebre del oro impulsa las inversiones en Nicaragua”, La Prensa, 7 de febrero, en línea: http:// www.laprensa.com.ni/20 I I/02/07/economia/5 I 365

Peters, Cristian, 20I4, "Guatemala afina su Corredor Interoceánico”, Construcción Latinoamericana, vol. 4, núm. I, pp. 57-8.

"Resumen 2013 en cifras", 20I3, Prensa Libre, 20 de diciembre.

"Pérez Molina dice en Taipéi que sigue en pie canal interoceánico", 2013, Prensa Libre, I7 de junio.

"Pobladores de San Marcos protestan por la falta de agua ante la mina Marlin”, 2013, Prensa Libre, 29 de junio.

Proyecto Mesoamérica, 2013, Programa Mesoamericano de Biocombustibles (PMB), Hojas Informativas, actualización al 3 I de noviembre, en línea: http://www.proyectomesoamerica.org/

Romero, Dora Luz y Moisés Martínez, 20I3, “El empresario chino secreto”, en línea: http://m.laprensa.com.ni/ reportajes-especiales/I52958

Smilovitz, Elie, 2012, "Los 10 países con las mayores reservas de oro del mundo", en línea: http://www.altonivel. com.mx/24394-los- I0-paises-con-las-mayores-reservas-de-oro-del-mundo.html

Van Sandt, Jons, 2009, Conflictos Mineros y Pueblos Indígenas en Guatemala, Cordaid, La Haya. 